\title{
Compassion Beyond Fatigue: \\ Contemplative Training for People Who Serve Others
}

John Makransky, PhD, Boston College

Chapter 8 in Meditation and the Classroom, ed. by Judith Simmer-Brown and Fran

Grace, SUNY Press, 2011

ABSTRACT: Teachers and others in helping professions or social service are taught the importance of listening with full attention, relating to students and clients in their deep worth, and discerning their hidden strengths. They are also cautioned to avoid burn-out. But how are such professionals to access in themselves the capacities of motivation, connection, discernment, and equanimity that are needed to fulfill those tasks? This article describes a contemplative training program designed by Makransky for those who serve others: such as educators, social workers, therapists, healthcare providers, hospice workers and social justice activists. Meditation practices from Tibet are adapted to help people of all backgrounds and faiths ease into a state of simple presence and compassionate connection with others, both for their own replenishment and to be more effective in their work with students and clients.

\section{Origins of the Compassion beyond Fatigue Workshop}

"Compassion beyond Fatigue" is the name of a contemplative training workshop that I developed for people in helping professions. In the workshop, guided meditations ease participants into a state of simple presence and compassionate connection with others. I have adapted these meditations from the "natural ease" tradition of Tibet (dzogchen) so as to make them accessible to people of all backgrounds and faiths. The purpose is to provide participants with contemplative techniques that can help them to alleviate burnout and compassion fatigue, to replenish energy and motivation, and to become more fully present to others. This essay describes the development of the program, its aims, some of the meditations taught, and how they inform the work of teachers and other helping professionals.

I began offering the "Compassion Beyond Fatigue" workshop in 2007 in the continuing education program at Boston College's Graduate School of Social Work. Since then I have offered it in diverse professional settings that have included educators, therapists and clinical psychologists, social workers, social justice activists, health care providers, pastoral counselors and ministers. ${ }^{1}$ The process that led to this workshop started seven years earlier when I began exploring new ways to adapt Tibetan Buddhist meditations of compassion, reverence and wisdom so as to make them more fully accessible to Western participants in meditation retreats sponsored by Buddhist centers. ${ }^{2}$

1 "Compassion beyond Fatigue" workshops are listed at: http://foundationforactivecompassion.org/, "calendar."

${ }^{2}$ See my recent book, Awakening through Love: Unveiling your Deepest Goodness (Wisdom: 2007) for fuller explanation of the meditations and how they were adapted from Tibetan praxis. I developed these techniques over the past nine years while teaching mainly in meditation retreats sponsored by Dzogchen Center 
Many of those who attended were teachers, professors and people in other service professions. A number attended multiple retreats and made a daily practice of the meditations. Many of these told me that they experienced more satisfaction and greater effectiveness in their work as they became more fully present to their students or clients. Several asked me to make the meditations available to a wider public of helping professionals in the secular world. As a result, I began to offer a "Compassion beyond Fatigue" workshop in diverse professional settings in 2007. In September 2008, together with Leah Weiss Ekstrom and Julie Forsythe, I co-founded a new organization, the Foundation for Active Compassion, which provides contemplative training for people in all types of social service and social justice profession. ${ }^{3}$

\section{Aims of the Compassion beyond Fatigue Workshop}

The meditations taught in the workshop aim to address three kinds of professional need which are elaborated in the following sections:

1- ALLEVIATING BURNOUT AND COMPASSION FATIGUE - Teachers and others in helping professions can benefit from tools to alleviate burnout and compassion fatigue. The meditations in this workshop help participants access a level of awareness beyond the dynamics of stress and burnout, where they can find deep rest, a sense of inner safety, and replenishment of energy and motivation.

2- BECOMING MORE FULLY PRESENT TO OTHERS - Teachers and other helping professionals are taught the importance of listening with full attention, of connecting to students or clients in their deep worth, and of discerning their hidden strengths. But how are these professionals to enhance in themselves the capacities of presence, connection, equanimity, patience and motivation that are needed to fulfill those tasks? The meditations in this workshop are designed to help participants evoke and increasingly actualize those capacities.

3- ENHANCING ONE'S ABILITY TO EFFECT CHANGE - Teachers, social activists and others in helping professions must often challenge dysfunctional patterns of behavior in students, clients and communities. Meditation tools can help them find more of the equanimity and inner strength needed to do so skillfully, while strengthening their compassion for everyone involved. ${ }^{4}$

\section{Alleviating Burnout and Compassion Fatigue}

At the beginning of each workshop I ask participants to tell what brought them there. Many report that they suffer from stress and burnout-feeling overwhelmed by frustrations with their students, clients, colleagues or dysfunctional institutional

(www.dzogchen.org), and also in retreats at the Barre Center for Buddhist Studies (www.dharma.org/bcbs) and Rangjung Yeshe Gomde Austria (www.gomde.de/eng/).

3 For information on the Foundation for Active Compassion and its social justice and social service programs, see: http://foundationforactivecompassion.org/

${ }^{4}$ My thanks to Leah Weiss Ekstrom for many informative discussions on the concerns and needs of social service professionals that informed my articulation of the three aims above. Thanks also to Julie Forsythe for many instructive discussions on social justice activism and service, and to Cathy Cornell for sharing her developing reflections on compassion fatigue, secondary trauma and contemplative practice. 
structures. There are feelings of resentment at being underappreciated or misjudged. There are sometimes harsh self-judgments_-blaming oneself for disappointing interactions and outcomes.

Workshop participants often use the term "compassion fatigue" in a broad way to signify their loss of compassionate connection to those they serve. Statements like these are common: "I used be so eagerly concerned for my students' welfare, but after years of teaching I feel so worn down that I've lost interest in them. It frightens me how little connection I now feel to my students." "I used to have so much compassion for my patients. Now it feels like I'm on autopilot." "I feel as though I have been giving and giving and giving and don't have any more to give. I need to be replenished, but don't know how."

Difficult external circumstances are the triggers for these problems, but people who come to this workshop want to continue in their professions. At work, they feel that they are caught in a self-perpetuating cycle of habitual reaction that they don't know how to free themselves from. They want to see if a contemplative practice can help them address this inner need at a deep level.

To help alleviate burnout and compassion fatigue, people need to find a place of inner refuge, a quality of awareness that is prior to the turmoil of ego reaction-a place of deep rest from their own reactivity and of profound replenishment for their energy and motivation.

There is a powerful contemplative method that can help the mind relax to that degree, a method that I adapted from Tibetan traditions for people of any faith or background to explore. The meditator vividly brings to mind loving, inspiring figures from her past and communes with them-receiving the energy of their loving compassion so deeply into her body and mind that her habitual, self-focused patterns of thinking and reaction can unwind and relax their grip. The meditation is done slowly, step-by-step, until the posture of self-concerned worry and reaction begins to fall apart of itself, accompanied by a sense of relief. When thoroughly familiarized with the practice, the mind can learn to relax so fully that it settles into its most natural, pre-conceptual state of simplicity, openness, and unobstructed awareness - a most profound letting be. That is where deepest rest and replenishment are found.

\section{Meditation One-Deep Replenishment: Communion, Union and Release into the} Natural State

Bring a few people to mind with whom you have felt happy, completely safe, well and loved (referred to here as "benefactors"). They can include people from any stage of your life, such as a favorite relative, teacher, camp counselor, mentor or friend. Your benefactors can also include deeply spiritual figures past or present whose presence in the world, or whose words, have inspired you-your spiritual ancestors.

Envision your benefactors' smiling faces before you. Imagine that they are sending you the wish of loving compassion - the wish for your deepest well-being, happiness and peace. Notice the joy of holding their smiling faces in mind. When you feel that joy, the meditation has already begun. It is the joy of sensing others commune with the goodness of your very being-your deep worth beyond all limiting value judgments. 
Feel the loving energy of this communing. Imagine it as a soft radiant energy, like a gentle, shimmering mist that comes from your benefactors and showers down upon your whole body and mind. Receive that soft, loving energy into every part of your body. First receive it deeply into your upper body, into every part of the face, head, neck, shoulders-letting all areas of tension soften and relax under its gentle touch. Then receive this soft radiant energy gradually into the middle part of your body: chest, back, abdomen, arms, and hands all the way down to your fingertips - allowing the gentle radiance to permeate every cell; letting bodily tensions relax under its touch. Finally receive the energy into each part of your lower body: torso, thighs, legs, all the way down to your toes-letting every part of you be loved.

After a little while, receive that loving, radiant energy into every part of your mind: into each layer of tension and worry; every feeling of difficulty, frustration, longing, sadness, grief, anger. Allow every feeling and thought in the mind, even as it arises, to be thoroughly permeated by this healing energy - sensing every part of you as loved. Do this for some time.

Then receive the loving energy into the subtlest feelings of holding onto your self, of holding onto anything at all. In this way, let yourself be tenderly swept away to merge into oneness with your benefactors and surroundings in that radiant energy. At this point, release the visualization and let your body and mind fall completely open. Allow all thoughts, feelings, and perceptions to just arise and dissolve of themselves like wispy clouds in sky-like openness. Let the mind rest in a state of utter simplicity and total expansiveness, allowing all to be just as it is.

This completes the first meditation.

To bathe so thoroughly in such loving energy, letting it permeate every thought and feeling, can be profoundly healing for the dynamics of burnout described earlier. When there is sufficient familiarity with this meditation, at the final stage of release, the mind can arrive at a simple, pre-conceptual level of awareness that is prior to ego reaction and discursive thinking, a place of most profound rest, peace and renewal - as if dropping below the choppy waves of a raging sea into its calm depth. In Buddhist terms, this is the place where our inmost capacity of tranquility and wisdom is heard from. It is from this place of deep inner peace and safety that we can best embody a sense of peace and safety for others.

\section{Becoming More Fully Present to Others}

The second meditation below follows from the one just completed. By letting our benefactors commune with our fundamental goodness and by deeply receiving loving energy (in the first meditation), we learn to relax into the ground of our being prior to all reactive thought - to find rest and replenishment in the openness and simplicity of preconceptual awareness. From that very place, in the second meditation, we can sense the same essential goodness, dignity and potential of all other persons around us, beyond anyone's limiting value judgments. We can commune with others in their deep worth and potential, just as our benefactors have done with us. To commune in this way is to tap our capacity for fuller presence to others, more positive energy, equanimity, discernment, patience and compassion. Meditation two thus moves us into the position 
of benefactor in relation to others - including our students or clients - bringing out our pre-verbal capacity for communing, connecting and affirming the best in them.

In the second meditation we repeat the first meditation above, then continue with the further instructions as below.

\section{Meditation Two-Deep Connection: Taking the Position of Benefactor for Others}

Begin by repeating Meditation One until you reach the final stage: letting the mind rest in its most natural state of simplicity and total openness. Sense the quiet power of that simple, undivided awareness.

After a little while, again recall your benefactors' smiling faces, this time imagining them behind you and just above. Feel the joy of holding their smiling faces in mind, sensing them commune with your essential goodness beyond anyone's limiting judgments. Feel the loving energy of this communing, imagining it as a gentle radiance that permeates your whole body and mind. Mentally repeat the wish of loving compassion for yourself so as to receive that energy even more deeply into your whole body and mind: "May this one have deepest well-being, happiness, and peace."

After a little while, bring to mind a person such as a family member, neighbor, student or colleague, and imagine him in front of you. While continuing to receive the loving energy from your benefactors behind, as if you were a windowpane, let that radiant energy come through you now to the person envisioned before you. Imagine this loving energy pervades his whole body and mind. As you do so, mentally repeat the same wish of loving compassion for him: "May this one have deepest well-being, happiness, and peace." While repeating that wish in your mind, commune with the goodness of his very being beyond limiting judgments, affirming him in his deep worth and dignity.

When you are familiar with the practice thus far, you can let the energy and wish of loving compassion gradually extend to further persons around you in widening circles, communing with each in their essential goodness and worth beyond limiting judgments, repeating the same wish for them all: "May they have deepest well-being, happiness, and peace." Do this step-by-step in widening circles at your own pace, including more and more of the persons and beings all around you.

After doing this for some time, imagine that the benefactors behind you dissolve into their loving energy and that energy dissolves into your heart. Then imagine that your heart, one with your benefactors, radiant like the sun, extends the same loving energy and wish to all persons in all directions at once, communing with them all in the goodness of their very being: "May all beings have deepest well-being, happiness, and peace."

Finally, let yourself be swept away by the loving energy, so that you merge into oneness in its radiance with all those beings and surroundings. Release the visualization, letting your body and mind fall completely open, letting all thoughts, feelings and perceptions arise and dissolve of themselves like wispy clouds in sky-like openness. Let the mind rest in a state of utter simplicity and total expansiveness, allowing all to be just as it is.

This completes the second meditation. 
In Meditation One, we received the loving energy of benefactors and merged with them, permitting the mind to relax into its most natural state of simplicity and openness. In Meditation Two, we drew upon the quiet power of that pre-conceptual awareness to bring out its capacities of connection and loving energy for others. By permitting our benefactors to commune with our deep worth and potential, we learn to commune with others in their deep worth and potential - including our students or clients. In this way, we learn to be more fully present to others in a simple, direct and deeply affirming way, beyond everyone's narrow judgments, reactions and prejudices.

\section{Progressing in Practice and Applying It in Life and Work}

Not everyone who attends these workshops is motivated to take up the meditations in a regular way. But a good many do. For them, I offer these tips for progress in practice.

Do daily practice of the first meditation above - communing with and deeply receiving loving energy from benefactors, merging into oneness with them, then letting your mind come to rest in its most natural state of simplicity and openness. Do that daily for weeks or months before proceeding to the second meditation.

When you take up the second meditation in daily practice-widen the circle of other persons with whom you commune day by day, while extending loving energy. When you feel the power of loving communion to be strong and stable at one stage of the meditation, you are ready to progress to the next stage, extending the energy and wish of loving compassion in wider and wider circles.

When you start to practice the second meditation regularly, try to do so in the morning. When you imaginatively extend loving energy to others in the morning meditation session, consciously include all the people that you will see and work with that day. When you are familiar with this practice, to meet those very people at your workplace triggers the gestalt of your morning meditation: bringing you back to simplicity, openness and compassionate connection with them. When this begins to happen, the quality of your presence to students and clients changes. Less distracted by habitual reactions, you can be present to others in a simpler way, connect pre-verbally to them in their deep worth and potential, listen more fully, sense their hidden strengths, and respond more creatively as the natural outflow of the compassionate communing that is already happening. 5

If you are a teacher, during morning meditation envision yourself receiving the radiance of loving compassion and letting it radiate through you to all your students. Later, when you step into your classroom, you begin communing with your students, radiating the energy of compassionate connection below the radar of narrow, selfconcerned judgments - theirs or yours. Let your wish for your students' well-being help evoke their capacities for discernment, compassion and joy in learning. Teachers and professors familiar with this practice tell me that they are amazed at how much more enjoyable and effective their classroom has become for themselves and for their students.

\section{Enhancing the Ability to Effect Change}

5 For detailed explanation of progress and integration of practice in life and work, consult Awakening through Love chapters five through seven. 
Notice how the second meditation extends the power of compassionate communing impartially to all other persons. All of us are socially conditioned toward limiting value judgments that are largely subconscious to us - judging some people as intrinsically more worthy of our concern, others as much less worthy. These meditations undercut that social conditioning, helping us to connect impartially to the immeasurable value of each person that transcends all limiting value judgments, including our own.

Although people in helping professions are routinely taught the importance of relating equally to the dignity and potential of all our students or clients, this can become merely an empty ideology if no specific way is provided to actualize the ideal in the quality of our presence to others. These meditations provide specific methods for gradual progress in that direction. The impartial, non-judgmental quality of loving compassion in these practices concerns value judgments. It does not, of course, imply that we should avoid making the judgments needed to help people learn or address their problems.

Social justice teachers and activists find the impartial quality of compassion in this practice especially meaningful. Many activists are motivated by anger at injustice and hatred for those who maintain the unjust social structures. Indeed, some consider this a primary motivation for their work, the other motivation being care for the victims of injustice. The activist may see himself as a champion for some and a scourge against others. But this can become self-defeating. Anger and hatred are painful to be around. They drive away potential supporters, trigger rage in one's opponents, polarize communities, and often burn out the social activist who gets consumed by his own rage.

The meditation practices above provide a different paradigm for social activism. Activism does not require two different motivations - compassion for some and hatred for others. One motivation - wise, enduring compassion - provides what is needed to challenge different people in different ways. People who suffer from injustice may need to be challenged to recognize their dignity and power to effect change. People who support unjust conditions may need to be challenged to recognize their connection to the poor and marginalized and their own greater human potential. Rather than being for some and against others, these practices structure a way to be for everyone, and from that very concern, to challenge different people differently. This approach is what can energize the social activist and inspire those around her for the long haul, like Gandhi, Martin Luther King and Thich Nhat Hanh have done.

Many teachers are social activists in their own spheres of influence, challenging not only their students but also parents and communities in support of children and their education. Here is one example. When a teacher or school counselor senses abuse in the home, she may sympathize with the student while harboring rage at the parent. Yet such parents were themselves often abused as children. To be present in a way that holds everyone involved in deep care, even as you challenge dysfunctional behavior, is more effective than suppressed rage. A contemplative practice that holds all in wise compassion can become deeply healing, first for the teacher herself, then for all those with whom she works.

\section{Can Non-Buddhists Take Up these Practices?}

Someone might ask, since these meditations draw upon Buddhist understandings of reality, is it possible for non-Buddhists to take them up? The meditations presented here adapt practices of compassion, reverence and wisdom from Tibetan Buddhism for a 
diverse, modern audience. ${ }^{6}$ They draw upon a Tibetan Buddhist (dzogchen/mahamudra) understanding that the underlying nature of our minds - prior to habits of thinking - is an unobstructed awareness of utter simplicity and openness which possesses a tremendous capacity of impartial love and compassion. Taking up these meditations requires exploring that understanding of the mind's nature in contemplative practice.

Certainly there are people whose beliefs would not permit them to explore in this way. However, in the past nine years of contemplative retreats and workshops, I have taught these meditations to thousands of Christians and Jews (including theologians, priests, ministers, and rabbis) and to many others of no formal religion, who have had no difficulty finding a place in their worldviews to explore these meditations in a serious way. Many of these people have taken up the practice regularly and reported the benefits mentioned above. Self-selection seems already to be answering the question. Indeed, what I most often hear from religious Christians and Jews is deep appreciation for the light these meditations have shed upon their own traditions and spiritualities. On the one hand, as the meditations described above expose how much mental energy we usually spend in narrowly self-centered distractedness, fear, and aversion, they help illumine Jewish and Christian understandings of sin as a real human problem. At the same time, for many Christian and Jewish practitioners, as these meditations evoke the power of presence and impartial compassion from beyond the narrow patterns of their egos, their faith in a transcendent power of love is reaffirmed. ${ }^{7}$ Non-religious participants, on the other hand, often express gratitude at discovering more of their own human capacity for inner peace and impartial compassion.

${ }^{6}$ On principles of adaptation, see Awakening through Love introduction and chapters 1 and 2.

${ }^{7}$ For one such example, see Awakening through Love, p. 240. 